\title{
Living With Breast Cancer; Sri Lankan Rural Women's Reflexive Responses to Emotional Challenges
}

\author{
H. P. N. I. Kumarasinghe * \\ Wayamba University of Sri Lanka, \\ Kuliyapitiya, Sri Lanka
}

\author{
U. K. Thalgaspitiya \\ University of Sri Jayewardenepura, \\ Nugegoda, Sri Lanka
}

\begin{abstract}
Breast Cancer incidence rate has risen consistently as the leading female cancer in Sri Lanka among rural population. Hence this study focused to identify the reflexive responses of Sri Lankan rural women living with breast cancer to Emotional challenges under three themes; Stress and depression, feeling solation and spiritual directions. Qualitative research approach was adopted for this study and the data collected through semi-structured, in-depth interviews from twenty-four respondents. Research themes have been derived from First-level analytical coding approach and thematic analysis was used in analysis of collected data. Most of the women in the unit of analysis are stressed and feared more at the very first beginning of the breast cancer diagnosis. As a positive note no one could identify with depression conditions. Feeling isolation could identify with reduced social interaction mostly in younger women rather than elder. Finally, a greater extent of spiritual directions could reveal after the diagnosis of breast cancer as a coping mechanism of this illness and psychological well-being. Findings of this research can be applied to real world context when dealing with rural women who are living with breast cancer by everyone in the society. Application of identified reflexive responses may significantly contribute in building up coping strategies in counselling and psychology for breast cancer patients. There seemed to be no a considerable number of research studies in line with breast cancer and its challenges and responses in Sri Lankan rural context. Thus, along with these research findings, future researchers can investigate more depth in to this study including women in urban areas, different races, different religions, professionals and workers in variety of occupations also under many other research themes.
\end{abstract}

Keywords: Breast cancer, rural women, emotional challenges, reflexive responses, Sri Lanka

Received: 28 October 2020; Accepted: 19 February 2021; Published: 24 March 2021

\section{INTRODUCTION}

Cancer is rapidly increasing burden and is leading cause of death worldwide. Among them, breast cancer is a major health problem which causes death worldwide. 2.3 million women has diagnosed with breast cancer and 685000 deaths globally in 2020 and in the past 5 years by the end of 2020, there were 7.8 million women alive who were diagnosed with breast cancer, making it the world's most prevalent cancer [1]. Breast cancer is the most common non skin cancer among women, with as many as one in eight women diagnosed in their lifetime
[2]. It is second only to lung cancer as the leading cause of death due to cancer among women. Breast cancer can be identified as the leading cause of cancer mortality and the most frequently diagnosed cancer in developed and developing countries among female. There can be observed a gradual, significant increase in the female breast cancer in Sri Lanka [3]. The major reason behind this increase is the rapid rise in the breast cancer incidence among post-menopausal women.

Breast cancer is a challenging disease that impact hugely to the patient's psychological balance and a severe

\footnotetext{
${ }^{*}$ Correspondence concerning this article should be addressed to H. P. N. I. Kumarasinghe, Wayamba University of Sri Lanka, Kuliyapitiya, Sri Lanka. E-mail: hpni.kumarasinghe@gmail.com

(C) 2021 The Author(s). Published by KKG Publications. This is an Open Access article distributed under a Creative Commons AttributionNonCommercial-NoDerivatives 4.0 International License.
} 
burden for the patient and his/her family, generating huge impacts in terms of both physical and emotional aspects with the feelings of fear, hopelessness, guilt, desperation, and being abandoned [4]. Varity of emotional reactions could be seen at the moment of diagnosing breast cancer among rural women. [5] have mentioned that, "especially for those who equated breast cancer with death, the moment of diagnosis was described as having dramatic and negative psychological impact described as shock, emotional trauma, and devastation". Living as a family when the mother or wife in the family is diagnosed with breast cancer means living in a challenging, rearranged, and unknown reality, while struggling to regain ordinary life by the people the rural areas [6]. Women living with breast cancer suffer lot with many emotional challenges in the Sri Lankan context as well. But sometimes people around them or people commonly in the society cannot understand their responses. Emotional response is the immediate reflection to cancer diagnosis, significantly to breast cancer diagnosis in women [7]. Thus, not only the doctors, physicians but also the closest relatives around them should aware about the social, physical and psychological issues and challenges which the patients are facing. Unless they cannot understand their responses to those issues and challenges. So basically, it is important to identify the emotional challenges of rural women living with breast cancer. Number of researches, studies have been done on major psychological challenges of breast cancer patients in the world while no considerable number of studies done in Sri Lanka. And their responses to those challenges have not been discussed and analyzed mostly. Therefore, the main objective of this study is to examine the reflexive responses to emotional challenges of rural women living with breast cancer in Sri Lanka.

Specially breast cancer is widening all over the world in recent years and massive number of patients are suffering with such illnesses in their rest of life. [8, 9] has identified main three emotional challenges of breast cancer patients; Feeling Isolation, Coping with financial burden and spiritual direction. There seemed to be no a considerable number of studies in line with breast cancer and its challenges and responses in Sri Lanka. So, it is important to identify their responses to challenges for building up coping strategies in counseling and psychology as well. Although the women with breast cancer gets recovered, they must live the rest of the life with many side effects of socially, psychologically and physically as well. So, their challenges remain with their life. Hence it is important to know how they react and response to those challenges for themselves to build and rise again within their lives.

Women perception on breast cancer and its treat- ments can impact to occur changes in their roles and relationships within the family and in the society. [10] say "diagnosis and treatment can rob people of family and social roles, which causes emotional distress for all involved". The patient with breast cancer experiences meets lot of emotions felt throughout the illness trajectory, the significance of religion and family uphold on adapting techniques utilized to deal with the symptoms of chemotherapy and money related concerns [11]. Support and encouragement received from friends had felt good to be prepared for the side-effects of treatment [12]. Accordingly, it is important to know their responses by the closest people around them to support her emotionally.

Not by themselves and closest people around them, but also knowing the responses for emotional challenges of women living with breast cancer are significant for the doctors, physicians, psychologists, counsellors and etc., who move around with those kinds of patients to build coping strategies for them. Thus, his study focuses on going insight to in-depth qualitive study through main three themes as Stress and depression, feeling isolation and spiritual directions by adopting thematic analysis.

\section{LITERATURE REVIEW}

Noncommunicable diseases are now responsible for most of global deaths, and cancer is relied upon to rank as a main source of death and the absolute most significant boundary to expanding future in each nation of the world in the 21st century [13]. [14] says "for many cancers, incidence rates could increase substantially in the future, with up to 15 million new cases in 2020, most of which will be in developing countries".

Breast cancer can be identified as a common disease in worldwide within women which is still rising rate with the years mostly in developing countries as well as in low- and middle-income countries including Sri Lanka. According to the prior researches done by various scholars, breast cancer is a challenging disease which rural women are coping with many social and psychological challenges more than the cancer.

Breast cancer is equally common in developing countries as well as in developed countries while it can be identified as the most prevalent type of cancer in the ranking at two [15]. The global occurrence of breast cancer is nearly three times higher than its' next, colorectal cancer and it is the biggest cause of cancer among women. Situation in the Sri Lanka is same. As per WHO gauges, roughly 4000 Sri Lankan ladies are determined to have breast cancer and very nearly $33 \%$ of this number capitulate to breast cancer every year [16]. So, the breast cancer can be identified as rising threat to women all around the 
world that should concern highly. According to the details in the reports of International Agency for Research on Cancer (IARC), due to the rates of lower cancer specific survival, high number of breast cancer deaths occur in developing countries. Studies have appeared that the most prominent increment will be among women in developing nations, a larger part of whom live within the Asian locale and most thinks about on rate and patterns in breast cancer rate have been detailed in developed nations, whereas analyzes of these patterns and designs in developing nations, counting Sri Lanka, are constrained [3]. Anyhow breast cancer screening services are now provided with the involvement of Medical Officers of Health $(\mathrm{MOH})$ in respective $\mathrm{MOH}$ areas in Sri Lanka.

\section{A. Rural Women with Breast Cancer}

Rural population refers to people living in rural areas defined by national statistic offices. According to the development indicators of World Bank, $81.89 \%$ out of total population was reported in 2019 as rural population in Sri Lanka and Rural women population reported as 41.99\% in 2015 (World Bank, 2020). Breast cancer crude incidence rate 28.8 per 100,000 female population and most of them could recognize among the rural women population [17]. This has risen in the recent past. So, women with breast cancer in rural areas face many difficulties rather than in urban areas. Rural women may experience specific concerns due to their geographical location along with the diagnosis, and the difficulties of living with breast cancer, [18]. These concerns relate to their distant from urban areas and specialized health services: and to particular challenges in rural life, including rural unemployment, reducing farming incomes, drought, declining population, closing of businesses and services and the loss of farms by families who had been living for a long time [19].

\section{B. Emotional Challenges}

Cancer patients suffer more emotionally compared to other patients and diagnosis of breast cancer itself is a terrible challenge for a woman [20] The issue of breast cancer is an emotional one that affecting various responses and reactions from women [11]. Emotional functioning, which impacts the capacity to enjoy life, is influenced and this causes enthusiastic responses such as being bad-tempered, misery, need of resilience, severity, and fear of torment and passing [21]. For many women, the psychologicsl measurement of breast cancer is an imperative viewpoint of the illness. Because it may not as it were increment her body awareness which can result in misfortune of self-esteem, but it can too have an en- thusiastic impact [11]. A study by [22] has confirmed that even the altered body image is a critical psychosocial issue for a breast cancer patient. Briefly women who experience greater psychological and physical problems as result of breast cancer may have greater difficulty in coping [23].

Stress and depression can be identified as common psychological/ emotional challenges that that cancer patients face. Specially it will be a huge burden for rural women to cope with breast cancer while facing to life challenges. Most of the ladies had children in young age and were depressed and constantly worried by the uncertainty of treatment outcome and the future of their children [11]. Depression can be seen in every level of treatment. Researchers has shown that psychological morbidity such as helplessness/hopelessness, hostility and guilt, chronic stress, extroversions and cognitive disorders, lack of happiness and negative mood, stressful life events, lack of perceived social support, obsessive-compulsive symptoms, coping problems one-third of women in the first two years after treatment [24].

[4] also has listed psychosocial factors that arise due to breast cancer. Some of them are personality structure, sociocultural features, psychosocial stress factors, negative feelings such as death threat, coping methods, past experiences, lifestyle, and genetic characteristics. In a similar study done by [25] also has revealed many of the women who participated for the study was having struggled with a sense of isolation, both in their home setting and in the urban setting. But the problems associated with rural living women has appeared to be more strongly felt by being alone with their experiences in rural setting and this was related to the lack of professional support, unable to speak of their true feelings because they wanted to protect loved ones, or because they felt a real lack of privacy and confidentiality in their communities [18]. And also, anxious women tend to be over involved, intrusive, and controlling too [26].

Through spiritual directions, rural women are fighting with the breast cancer to have a relief psychologically. Spirituality has been used by women as a source of comfort too reduce the fear and uncertainty and to give them the strength to fight the disease, tolerate the treatment and look to the future [11]. As [10] cited from Venter, 2008:27, "people can draw strength from their faith or relationship with God, which positively affects their ability to cope". [7] also could revealed that breast cancer patients are praying helped them to cope with problems, standing the crisis that resulted from cancer diagnosis through spiritual prayers. 


\section{METHODOLOGY}

\section{A. Study Context}

To investigate the underlying research questions on how Sri Lankan rural women living with breast cancer response to emotional challenges, the researchers' focus was on discovering personal stories, experiences, and psychological changes during and after the diagnosis and how they respond to those. This Research has been undertaken over 3 months and engaged with rural breast cancer patients who are fully recovered while some are still taking treatments. The data collection followed the method of semi- structured and in-depth interviewing and the process resulted in 24 interviews with self-selected breast cancer patients. The Interviews were in various locations and using methods (face to face or Tele-communication) based on respondents' preferences. Some interviews were done with the relatives of the patients. Same study contexts and interviewing method has been used by [5] in a study similar to this research study.

The participants as self-narrators use their life stories to with the breast cancer and to highlight the events that they perceived as significant. Each interview started with respondents telling their story of symptoms and diagnosis in their own words. In few cases, participants narrated their stories outside the guide too. Participants discussed different aspects of their experiences in hospitals, clinics, work places, and family members and friends and the initial reaction to this event regarding emotional issues.

\section{B. Participants and Data Analysis}

The study involved 24 participants including 16 rural women who were/are living with breast cancer and 8 were relatives of the rural women with breast cancer. When reporting their responses, they have clustered in to 2 groups to reflect their response and perspectives clearly. First group named as Direct Patients (DP) and the second group named as Relatives of the patients (RP). Each participant was assigned a two-part code, which starts with two letters followed by a digit. The two letters represent the group in which the participant belonged, and the digit is the individual participant's identification code.

TABLE 1

SAMPLE PROFILE

\begin{tabular}{|c|c|c|c|c|c|c|}
\hline $\begin{array}{l}\text { Patient Code } \\
\text { No. }\end{array}$ & Age & District & Occupation & Marital Status & No. of Children & Current Status of Cancer \\
\hline DP-1 & 53 & Puttlam & Housewife & Married & 4 & Recovered \\
\hline DP-2 & 55 & Kurunegala & Retired Teacher & Married & 2 & Recovered \\
\hline DP-3 & 37 & Kaluthara & Housewife & Married & 2 & Taking treatments \\
\hline DP-4 & 52 & Kalutara & Housewife & Married & No & Recovered \\
\hline DP-5 & 40 & Galle & Farming & Married & 2 & Taking Treatments \\
\hline DP-6 & 39 & Kurunegala & Housewife & Married & 2 & Taking Treatments \\
\hline DP-7 & 54 & Puttlam & Farming & Married & 2 & Taking Treatments \\
\hline DP-8 & 58 & Anuradhapura & Retired Clerk & Married & 3 & Taking Treatments \\
\hline DP-9 & 46 & Kurunegala & Hospital Attendant & Divorced & No & Taking Treatments \\
\hline DP-10 & 42 & Kurunegala & Teacher & Single & No & Taking Treatments \\
\hline DP-11 & 51 & Matara & Tailoress & Married & 2 & Recovered \\
\hline DP-12 & 53 & Galle & Housewife & Married & 3 & Taking Treatments \\
\hline DP-13 & 61 & Gampaha & No & Married & 3 & Recovered \\
\hline DP-14 & 38 & Gampaha & Office Assistant & Single & No & Taking Treatments \\
\hline DP-15 & 52 & Kegalle & Teacher & Widow & 2 & Recovered \\
\hline DP-16 & 56 & Galle & Tea Plucker & Married & 3 & Recovered \\
\hline RP-1 & 45 & Nuwaraeliya & Housewife & Married & 5 & Taking treatments \\
\hline RP-2 & 35 & Kandy & Bank officer & Married & 1 & Taking treatments \\
\hline RP-3 & 56 & Anuradhapura & Retired Teacher & Married & 2 & Recovered \\
\hline RP-4 & 48 & Kurunegala & Housewife & Married & 2 & Taking Treatments \\
\hline $\mathrm{RP}-5$ & 46 & Matara & Housemate & Widow & No & Taking Treatments \\
\hline RP-6 & 51 & Kurunegala & Farming & Married & 3 & Taking Treatments \\
\hline RP-7 & 54 & Badulla & Cleaner & Married & 2 & Taking Treatments \\
\hline RP-8 & 62 & Gampaha & No & Married & 3 & Recovered \\
\hline
\end{tabular}


TABLE 2

THEMES AND CODES

Themes First Level Codes

Stress \& Depression

Changes in feelings when being diagnosed as a breast cancer patient

Way of coping with stress and depression

Feeling isolation

Changes in social interactions

Felling helplessness

Spiritual directions

Extent of engage in religious activities

Impact for psychological relief

The researcher selected the qualitative approach as methodology of this study. Then identified three main themes that interprets the emotional challenges of Rural women with breast cancer through prior literature and the existing knowledge. So, the thematic analysis was used to interpret and discuss the findings. Same research approach, coding and thematic analysis has adopted by [5] to analyse Arab American women's lived experience with early-stage breast cancer diagnosis and surgical treatment and [7] to analyse the leved experiences of Iranian women confronting breast cancer diagnosis.

\section{FINDINGS}

\section{A. $\quad$ Stress and Depression}

Normally most symptoms of stress and depression can be recognized in breast cancer women in western literature. It is the same in Asian countries too. According to the experiences and the responses of this research respondent's majority of them were highly stressed at the very first beginning of the breast cancer diagnosis. But significantly no one was identified suffering with depression.

Under this, purpose of the interviewer is to identify and get an understanding about emotional changes of rural breast cancer women when they are being diagnosed as a breast cancer patient at the very first. 23 of 24 respondents said they were feared and stressed when they diagnosed it. DP-4 who is a housewife with no children mentioned that she didn't feel anything bad especially due to this. Except her, all others were feared and stressed about many things in their lives when they were diagnosed as breast cancer patients.

Some patients and their relatives didn't want to allow the patient to remind their sad situations and experiences again and again. So that, to avoid the inconvenience occurs within some women with breast cancer, their closest relatives talked with the interviewer to give data regarding the responses of the patient with the consent of the patient.
Majority of the patients suffered with stress but significantly no one wasn't being suffered with depression situations. They had good ways to cope with psychological stress. So that their sufferings haven't not let them to develop as depressed situations. Any one didn't want special or separate medical support to cope with stress. All of their coping mechanisms were support given by closest members of the family and the religious prayers and guides.

Respondents of the RP group shared their ideas about the stress and depression related to their patients very well. They had seen how they cope with this challenge.

\section{B. Feeling Isolation}

Breast cancer creates psychological pressure for women since it affects to the changes physically, mentally and socially as well. So, at the very first beginning of the diagnosis of breast cancer, they have felt helplessness and changes happened in social interactions in different levels. Extent of feeling helplessness and changes of social interactions differ one to another, some women said that they didn't feel isolation or helplessness since they have a good support from others. And also, they mentioned no any changed occurred in the social interactions, but majority of them had felt helplessness and changes in the social interactions in some occasions.

Mostly these rural women living with breast cancer feel helpless due to the challenges they face even there are supportive people around them. In contrast to above majority's responses two women said that they didn't feel such helplessness due to the breast cancer.

Breasts are significant body part for women. So, having cancer of them is a big problem for such ladies. Sometimes they are unwilling to go to the society because of the curiosity arise regarding the perception of others towards them. Then they might fear to interact with others.

Different level of changes and no changes could be identified by the researcher related to the sample selected. According to the responses of four were no a change 
in social interactions of those rural women living with breast cancer. Others have a dislike of talking to others at the beginning. But later, they have used it. One respondent mentioned that, at the beginning patient had usual interaction with others, but now she doesn't like to participate in functions where lot of people are gathering due to knowing her limits of life span.

\section{Spiritual Directions}

Except one woman all others a greater extent of engage in religious activities in order to have blesses and psychological relief through that. These spiritual directions/religious prayers had been a big strength for them to minimize their fear and cope with stress successfully. So, the findings related to the extent of engage in religious activities and the psychological relief they had through it are mentioned under this.

Normally Sri Lankan people used to engage in more religious activities when they are in unhealthy situations in order to relax their mind. So, these rural women living with breast cancer are also have a greater extent of engagement of their religious activities.

RP-3 highlighted that except to religious observances, his mother and the family believed in myths also in some occasions. Myths like there are persons who can cure the patients through his spiritually developed mind. But he said it was useless, but they went after such people due to the patients' and their helplessness. And DP-1 said that she had a little influence from people in another religion to take her for prayers. But however, she has rejected them and understood only prayers cannot cure from this disease.

A big psychological impact for these rural women living with breast cancer could identified by the researcher through the engagement of religious activities. Relatives of the patients also significantly described how those spiritual directions can strengthen their patents' endurance and coping abilities. RP-3 mentioned that, spiritually being strong is very important for a lady to cope with a chronic disease like breast cancer.

\section{DISCUSSION}

\section{A. Stress and Depression}

1) Changes in feelings when being diagnosed as a breast cancer patient: At the stage of diagnosing the breast cancer, most women were sacred and worried about the life. Several studies have found that elevated levels of distress, anxiety and depression is experienced by many women with breast cancer.Some studies have found that many breast cancer patients experienced fear of the cancer spreading or recurring, debilitating treatment side effects such as fatigue or nausea, poor self-esteem and body image [27]. [2] has revealed that approximately one-quarter of patients claimed distress or anxiety in his study. In this study majority of women felt fear, worry when diagnose the breast cancer and after that also due to physical and social changes.

“[I] feel feared, my god feel feared lot. [I] can't say how it felt, couldn't even eat, drink. [I] was staying crying. I was afraid when hearing that breast will cut off and removed" (DP-1).

"Actually, I was scared so much. I felt feared about my future and uncertainty about the life when I heard about the word breast cancer. And also, I couldn't believe with my age that I have a cancer. But however, I had to accept that" (DP-3).

2) Way of coping with stress and depression: Luckily these Sri Lankan rural women who are living with breast cancer hasn't suffered with depression anytime although they had stressful symptoms. They could cope with stress mainly by engage in spiritual activities and with the family and community support. Family members and closest people give a greater support to maintain the emotional wellbeing. Similar finding has investigated by other researchers. Emotional support and instrumental support offer by family members and appraisal support offers by peers enhance the individual's self-esteem to cope with emotional instability [28].

In this research, all the respondents' biggest coping mechanism of stress was the religious activity engagements. All the rural women in the unit of analysis were Buddhists. Most of them has understood uncertainty and the truth of the life through Buddhism teachings after the diagnosis of breast cancer. It was a great strength for them to cope with the emotional issues. One woman mentioned that mediation was her best mechanism of coping with turbulent mind.

"Actually, I had a stress, [I] had a huge stress of how I face to this disease with my kids. I had heard about this cancer and it's suffering earlier. Kids also don't have an understanding about what their mother is suffering. They are asking many things and I cannot answer them sometimes. So, I'm being so sensitive at those times and get stressed. But I didn't need a special medical treatment to overcome that. My mother, family members and surrounding people are making my mind, doctors too advise not to fear when going to take treatments. So, any depressed situation didn't occur" (DP-3)

"At the beginning she got angry lot, cried, tried to separate from others and like those things could be seen with her. But with the interference of us and specially with advices from the Monk of the village temple, she could 
handle the stress situation without going to a situation like depression" (RP-2). So, the main coping strategies of stress were family and community support and engage in religious activities according the views the respondents of this research.

\section{B. Feeling Isolation}

1) Feeling helplessness: While some women didn't feel helplessness due to the great family and community support, some have been helpless due to many circumstances. When their husband not at home, those women are difficult to cope with illness while managing all other things like household activities, parenting ant etc. Inability of working efficiently due to physical weakness was a constant reminder of this disease for many women [11]. Such women feel helpless rather than others.

"To a greater extent I did everything myself alone. No one is there, I went to hospital alone by bus. Most of the times I was alone in the hospital, once I was in the Anuradhapura Hospital, people were coming to see other patients no one came to see me, others were asking why anyone was not coming, So, I'm saying it is difficult them to come, daughters have small kids and others also have works. I felt so alone and helpless" (DP-1).

"At the very beginning of breast cancer diagnosis, she worried so much, she cried and got angry, her daughter is very small, still she is living with little sadness" (RP-5).

2) Changes in social interactions: Women emphasized the need to be alone, preferred not to talk or discuss issues with people and also experienced a dislike of being surrounded by other people, because of the fear of being a topic for others to gossiping. Similar finding has revealed by [11]. Some of the women do not like to attend to functions Women expressed that they disliked meeting people and family members and preferred not to attend family functions and weddings [11]. But some older women who had social interaction to a greater extent hadn't much changes, they even went to the job without any doubt after removing both breasts.

"Actually, at the beginning I had a little fear to face the society because I don't know how they will see and interpret me. So, I have a little dislike of going out because when they are always asking about my conditions, it is a pressure for me, my sadness and stress renew again and again, but since it has gone more than one year, I'm used to it now" (DP-10).

"She is a social woman, [she] treats others very well. As usual she talks with others and interact with others, but now she has reduced going to functions like earlier. Because she knows that there is a limit for her life time now" (RP-1).

\section{Spiritual Directions}

1) Extent of engage in religious activities: Except one woman all others had a greater extent of engage in religious activities after the diagnosis of breast cancer. They have practiced and done meditation, Pirith chanting, Bodhi Pooja, Arms giving, reading religious books and etc. one respondent said that they believe in myths also due to the helplessness that the patient and the family felt. But those were not useful for any positive change of the patient. Other women had some influence from people who in another religion to go through on their religious perspectives, but she has rejected them and engage in religious activities according to Buddhism teachings. Some have prayed for gods. The same finding could be revealed by [11] regarding Muslim women with breast cancer in Pakistan. Although they are belonging to two religions, they believe that they could have a relief through their religious observances.

"Actually, I engage in religious activities to have blesses and mental relax than before. Husband takes me to temple. We did Bodhi Pooja and a Pirith chanting even at home" (DP-12)

"Normally she is a lady who lived a peace life, but I saw significantly she engages in more religious activities rather than before, read religious books also" (RP-6).

"She is a Buddhist; we believe sin and merit. We did so many religious activities to bless her. She also practices meditation. Monk of our village temple also always advises her. And we are going to the Temple of Secret Tooth Relic also. We pray to the gods also" (RP-3).

2) Impact for psychological relief: Those women who are living with breast cancer had a greater psychological relief through the spiritual directions. It was their coping mechanism. Another researcher also had the same idea. Religious beliefs were viewed as a source of strength which has a positive impact on their outlook [29]. They could cope with stress and fear. Some were able to understand the truth and the uncertainty of the life. [5] also has revealed religious activity as a coping mechanism in their study of analysing life experience of Arab American breast cancer patients.

"Now I'm always ready to face anything what would happen in the future. It is no matter for me, always monks are saying to collect merits for both this life and next life. So, now I understand the life is uncertain and death is certain" (DP-7).

"I really tend to religious activities to a greater extend, actually I could have a relief through that. My fear also could release, meditation was my best way to relax my mind" (DP-2).

"With tending to more religious activities, I could 
have a mental relief and could minimize the fear" (DP-3).

"I could control my emotions through those religious activities" (DP-13).

\section{CONCLUSION}

This study focused to identify the reflexive responses of Sri Lankan rural women living with breast cancer to emotional challenges under the themes of stress and depression, feeling isolation and spiritual directions, adopting qualitative approach and data collected through semistructured interviews. First-level analytical coding approach was used to derive themes and thematic analysis was used in analysis of collected data. Among the major findings, most of the women in the unit of analysis are stressed and feared more at the very first beginning of the breast cancer diagnosis and also in later periods too due to lack of proper support and other challenges. As a positive note no one could identify with depression conditions. Feeling isolation could identify with reduced social interaction mostly in younger women rather than elder women. Finally, greater extent of spiritual directions could reveal through twenty-three women except one after the diagnosis of breast cancer as a coping mechanism of this illness and psychological well-being. Family and community support and spiritual directions should be further promoted so as to maintain emotional well-being of the rural women living with breast cancer, since those could be identified as major mechanism of coping with stress, isolation and fear.

\section{A. Limitations and Study Forward}

There were some limitations while conducting the research such as difficult to collect in-depth data from patients who are under treatments, some patients may not like to express their true ideas. difficult to access to rural areas to meet direct patients and limitation in considering large group of samples of the rural women living with breast cancer Sri Lanka.

Future researchers can investigate more in-depth to this study including women in urban areas, different races, different religions, professionals and workers in variety of occupations also under many other research themes.

\section{REFERENCES}

[1] World Health Organization. (2012) World health statistics 2012. [Online]. Available: https://bit.ly/3lfWpyK

[2] J. R. Schubart, M. Emerich, M. Farnan, J. S. Smith, G. L. Kauffman, and R. B. Kass, "Screening for psychological distress in surgical breast cancer patients," Annals of Surgical Oncology, vol. 21, no. 10, pp. 3348-3353, 2014. doi: https://doi.org/10.1245/ s10434-014-3919-8

[3] A. Fernando, U. Jayarajah, S. Prabashani, E. A. Fernando, and S. A. Seneviratne, "Incidence trends and patterns of breast cancer in Sri Lanka: An analysis of the national cancer database," $B M C$ Cancer, vol. 18, no. 1, pp. 1-6, 2018. doi: https: //doi.org/10.1186/s12885-018-4408-4

[4] F. İzci, A. S. İlgün, E. Fındıklı, and V. Özmen, "Psychiatric symptoms and psychosocial problems in patients with breast cancer," The Journal of Breast Health, vol. 12, no. 3, pp. 94-101, 2016. doi: https://doi.org/10.5152/tjbh.2016.3041

[5] R. F. Obeidat, R. M. Lally, and S. S. Dickerson, "Arab American women's lived experience with early-stage breast cancer diagnosis and surgical treatment," Cancer Nursing, vol. 35, no. 4, pp. 302-311, 2012. doi: https://doi.org/10.1097/NCC. 0b013e318231db09

[6] A. Holst-Hansson, E. Idvall, I. Bolmsjö, and A. Wennick, "Hoping to reach a safe haven-Swedish families' lived experience when a family member is diagnosed with breast cancer," European Journal of Oncology Nursing, vol. 31, pp. 52-58, 2017. doi: https://doi.org/10.1016/j.ejon.2017.10.003

[7] E. Mehrabi, S. Hajian, M. Simbar, M. Hoshyari, and F. Zayeri, "The lived experience of Iranian women confronting breast cancer diagnosis," Journal of Caring Sciences, vol. 5, no. 1, pp. 43-55, 2016. doi: https://doi.org/10.15171/jcs.2016.005

[8] H. P. N. I. Kumarasinghe and U. K. Thalgaspitiya, "Living with breast cancer; Sri Lankan rural women's reflexive responses emotional challenges," in 8th International Conference in the series of youth 2025, Jaipuriya, India, 2021.

[9] H. P. N. I. Kumarasinghe and U. K. Thalgaspitiya, "Living with breast cancer; Sri Lankan rural women's reflexive responses to social and emotional challenges," in 16th International Conference on Business Management (ICBM), Colombo, Sri Lanka, 2019.

[10] J. van Wyk and C. Carbonatto, "The social functioning of women with breast cancer in the context of the life world: A social work perspective," Social Work, vol. 52, no. 3, pp. 439-458, 2016. doi: http://dx.doi.org/10.15270/52-2-518

[11] M. Banning, M. Hassan, H. Hafeez, S. Faisal, and A. Zafar, "The impact of culture, sociological and psychological issues on Muslim breast cancer patients in Pakistan," Cancer Nursing, vol. 34, no. 4, 
pp. 317-24, 2009. doi: https://doi.org/10.1097/NCC. 0b013e31819b240f

[12] E. M. Sawin, “"my husband would not help me, so i was driving over there': Older rural women experiencing breast cancer with a non-supportive intimate partner," Rural and Remote Health, vol. 10, no. 4, pp. 1-13, 2010.

[13] F. Bray, J. Ferlay, I. Soerjomataram, R. L. Siegel, L. A. Torre, and A. Jemal, "Global cancer statistics 2018: GLOBOCAN estimates of incidence and mortality worldwide for 36 cancers in 185 countries," CA: A Cancer Journal for Clinicians, vol. 68, no. 6, pp. 394-424, 2018. doi: https://doi.org/10. 3322/caac. 21492

[14] P. Kanavos, "The rising burden of cancer in the developing world," Annals of Oncology, vol. 17, pp. 15-23, 2006. doi: https://doi.org/10.1093/annonc/ md1983

[15] American Cancer Society. (2013) Cancer facts \& figures. [Online]. Available: https://bit.ly/3ahTfEc

[16] S. Seneviratne, "Dr. RL Spittel oration: A breast cancer registry to improve quality and reduce disparities in breast cancer care-lessons learnt," Sri Lanka Journal of Surgery, vol. 34, no. 4, pp. 16-20, 2016. doi: http://doi.org/10.4038/sljs.v34i4.8316

[17] National Cancer Control Programme. (2014) Cancer incidence data in Sri Lanka. [Online]. Available: https://bit.ly/3iFoTAp

[18] C. Rogers-Clark, "Living with breast cancer: The influence of rurality on women's suffering and resilience. a postmodern feminist inquiry," Australian Journal of Advanced Nursing, The, vol. 20, no. 2, pp. 34-39, 2002.

[19] S. J. Coakes and G. J. Kelly, "Community competence and empowerment: Strategies for rural change in women's health service planning and delivery," Australian Journal of Rural Health, vol. 5, no. 1, pp. 26-30, 1997. doi: https://doi.org/10.1111/ j.1440-1584.1997.tb00231.x

[20] S. M. S. Baqutayan, "The effect of anxiety on breast cancer patients," Indian Journal of Psychological Medicine, vol. 34, no. 2, pp. 119-123, 2012. doi: https://doi.org/10.4103/0253-7176.101774

[21] M.-L. Luoma and L. Hakamies-Blomqvist, "The meaning of quality of life in patients being treated for advanced breast cancer: A qualitative study," Psycho-Oncology: Journal of the Psychological, So- cial and Behavioral Dimensions of Cancer, vol. 13, no. 10, pp. 729-739, 2004. doi: https://doi.org/10. 1002/pon.788

[22] C. Pierrisnard, M. Baciuchka, J. Mancini, P. Rathelot, P. Vanelle, and M. Montana, "Body image and psychological distress in women with breast cancer: A French online survey on patients' perceptions and expectations," Breast Cancer, vol. 25, no. 3, pp. 303-308, 2018. doi: https://doi.org/10. 1007/s12282-017-0828-2

[23] S. S. Brady and V. S. Helgeson, "Social support and adjustment to recurrence of breast cancer," Journal of Psychosocial Oncology, vol. 17, no. 2, pp. 37-55, 2000. doi: https://doi.org/10.1300/J077v17n02_03

[24] A. A. Malik and T. Kiran, "Psychological problems in breast cancer patients: A review," Chemotherapy, vol. 2, no. 2, pp. 1-6, 2013. doi: https://doi.org/10. 4172/2167-7700.1000115

[25] R. E. Gray, P. James, J. Manthorne, J. Gould, and M. I. Fitch, "A consultation with Canadian rural women with breast cancer," Health Expectations, vol. 7, no. 1, pp. 40-50, 2004. doi: https: //doi.org/10.1046/j.1369-6513.2003.00248.x

[26] B. R. Sprung, B. L. Janotha, and A. J. Steckel, "The lived experience of breast cancer patients and couple distress," Journal of the American Academy of Nurse Practitioners, vol. 23, no. 11, pp. 619-627, 2011. doi: https://doi.org/10.1111/j. 1745-7599.2011.00653.x

[27] A. Girgis, A. Boyes, R. W. Sanson-Fisher, and S. Burrows, "Perceived needs of women diagnosed with breast cancer: Rural versus urban location," Australian and New Zealand Journal of Public Health, vol. 24, no. 2, pp. 166-173, 2000. doi: https: //doi.org/10.1111/j.1467-842x.2000.tb00137.x

[28] M. C. Katapodi, N. C. Facione, C. Miaskowski, M. J. Dodd, C. Waters et al., "The influence of social support on breast cancer screening in a multicultural community sample," in Oncology Nursing Forum, vol. 29, no. 5. Oncology Nursing Society, 2002. doi: https://doi.org/10.1188/02.ONF.845-852 pp. 845-852.

[29] F. Taleghani, Z. P. Yekta, and A. N. Nasrabadi, "Coping with breast cancer in newly diagnosed Iranian women," Journal of Advanced Nursing, vol. 54, no. 3, pp. 265-272, 2006. doi: https://doi.org/10. 1111/j.1365-2648.2006.03808_1.x 